\title{
Association of HIV/AIDS and COVID-19 variables: an ecological study
}

\author{
Mohammad Sarmadi ${ }^{1,2}$, Abbas Ghodrati-Torbati ${ }^{2,3}$, Akram Gazerani ${ }^{4}$, Hamideh Yaghoobi ${ }^{2,3}$, \\ Hossein Bakhtiari-Dovvombaygi ${ }^{5}$
}

${ }^{1}$ Department of Environmental Health Engineering, School of Health, Torbat Heydariyeh University of Medical Sciences, Torbat Heydariyeh, Iran

${ }^{2}$ Health Sciences Research Center, Torbat Heydariyeh University of Medical Sciences, Torbat Heydariyeh, Iran

${ }^{3}$ Department of Nursing, School of Nursing and Midwifery, Torbat Heydariyeh University of Medical Sciences, Torbat Heydariyeh, Iran

${ }^{4}$ Department of operating room and anesthesia, Neyshabur University of Medical Sciences, Neyshabur, Iran

${ }^{5}$ Student Research Committee, Torbat Heydariyeh University of Medical Sciences, Torbat Heydariyeh, Iran

\begin{abstract}
Introduction: The coronavirus disease 2019 (COVID-19) has become the greatest critical healthcare concern in 2020. The present study investigated the correlation between COVID-19 distribution and the prevalence of human immunodeficiency virus/acquired immunodeficiency syndrome (HIV/AIDS) among countries.
\end{abstract}

Material and methods: Data were obtained from publicly available data on COVID-19 and HIV/ AIDS, such as the World Health Organization (WHO) and Global Burden of Disease (GBD). Bivariate correlation analyses were used to investigate the correlation between the variables.

Results: COVID-19 cases and death ratio negatively correlated with the prevalence of HIV/AIDS ( $r=-0.40$ and $r=-0.38, p<0.05$, respectively).

Conclusions: The findings indicated that in countries with high prevalence of HIV/ AIDS, COVID-19 cases and death ratio were low, which could be due to the type of therapy or screening system. Nevertheless, further studies are required in this field.

HIV AIDS Rev 2021; 20, 2: 71-77

DOI: https://doi.org/10.5114/hivar.2021.107233

Key words: COVID-19, prevalence, HIV/ AIDS, GIS.

\section{Introduction}

The coronavirus disease 2019 (COVID-19) pandemic have become a global healthcare threat in the world $[1,2]$. Globally, at the time of writing, 56,620,170 cases of COVID-19 have been confirmed, and 1,355,875 people have died from the disease [3]. Despite the increasing prevalence of the COVID-19 virus, the factors affected this disease are still not clear [4]. The COVID-19 pandemic has far-reaching consequences for individuals with multi-mor- bidity [5]. Patients suffering from various diseases, including high blood pressure, diabetes, and neoplasms, are among the high-risk groups for death and incidence of COVID-19 [6-8]. In fact, as the prevalence of COVID-19 increases, people with human immunodeficiency virus (HIV) would likely be at a greater risk of COVID-19. HIV infection is associated with abnormal humoral and T cell-mediated immune responses that can cause susceptibility to opportunistic infections [9]. Although, according to studies, the HIV/acquired immunodeficiency syndrome (AIDS) infection was
Address for correspondence: Hossein Bakhtiari-Dovvombaygi, Student Research Committee, Torbat Heydariyeh University of Medical Sciences, Torbat Heydariyeh, Iran,

e-mail: hs.bakhtiari1998@gmail.com
Article history:

Received: 09.03.2021

Received in revised form: 18.03.2021

Accepted: 26.03.2021

Available online: 30.06 .2021
International Journa of HIV-Related Problems

HIV \& AIDS

R e vi e w 
A

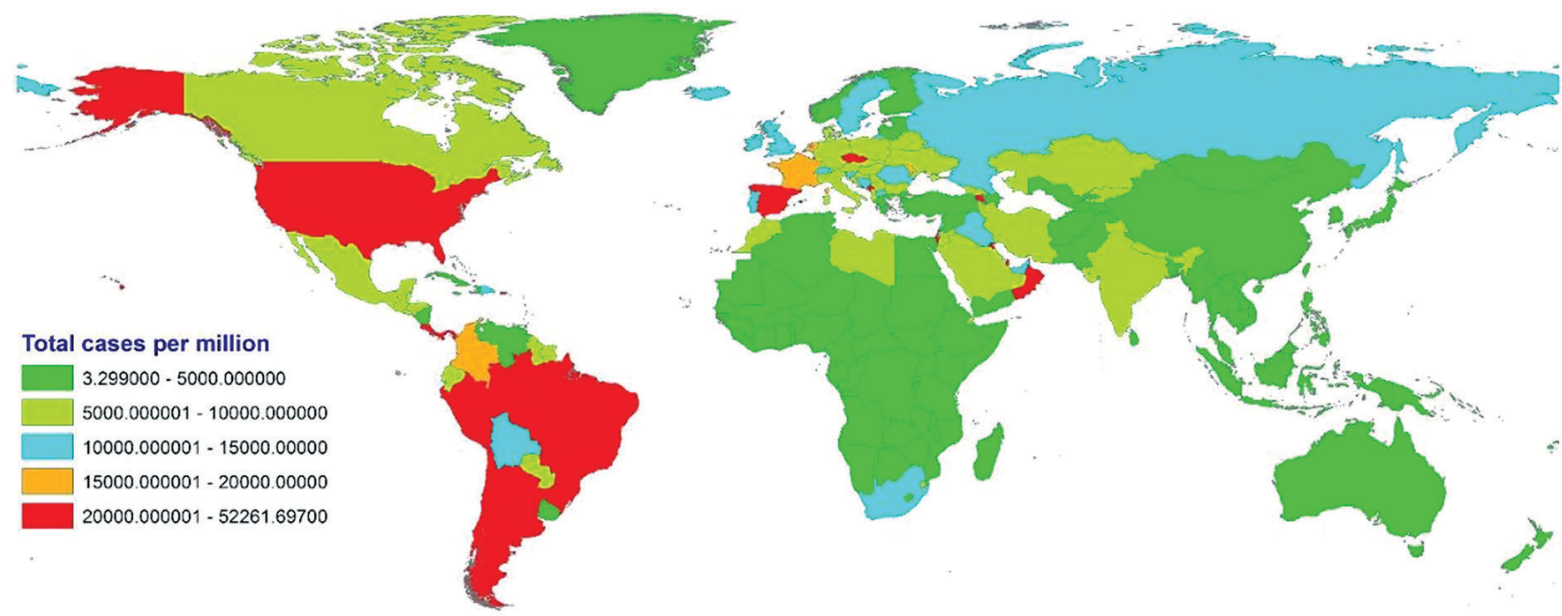

B

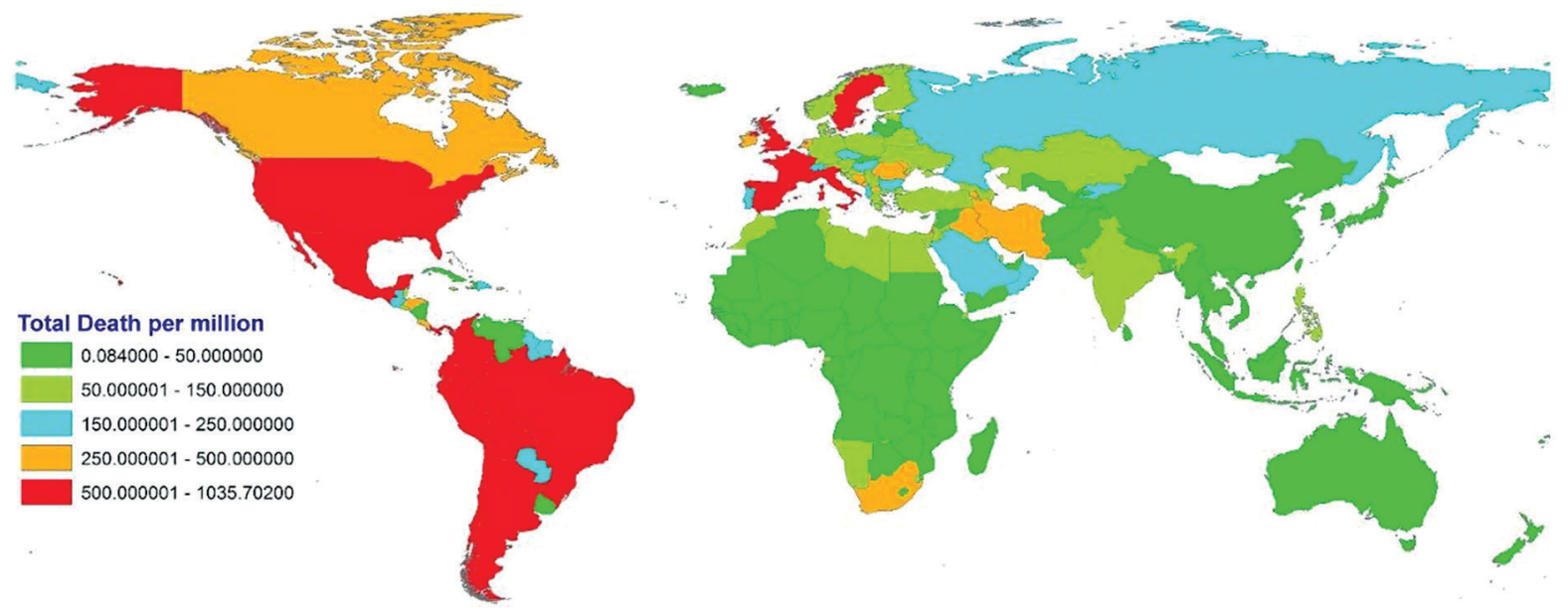

Figure 1. Cases and death per capita distribution of COVID-19 around the world

not reported as an important risk factor in hospitalized patients with COVID-19 [10-14]. One possible reason is that HIV-positive patients do not progress the extreme immunologic response that are frequently more difficult to clinical course of COVID-19. Also, another reason for low-risk of HIV and COVID-19 patients might be the results of their drug use, such as antiretroviral therapy (ART). ART was suggested as a protective factor against severe acute respiratory syndrome (SARS) in 2003. Hence, this study aimed to investigate the association between COVID-19 distribution and HIV/AIDS between countries.

\section{Material and methods}

This ecological study was carried out based on publicly available data on COVID-19, which was obtained from www.ourworldindata.org and the World Health Organization (WHO) website. In addition, we extracted the age-standardized prevalence, incidence, and death from HIV/AIDS and sexually transmitted infections from the Global Burden of Disease (GBD) dataset. The socio- demographic index (life expectancy, median age, age up to 65 , and age up to 70), gross domestic product (GDP) per capita as socio-economic demographic factors were taken from online databases, including the GBD [15], World Bank [16], and United Nations Development Program (UNDP) websites [17].

Descriptive statistical analysis was conducted for all the variables. Correlation coefficients of COVID-19 variables (proportion of the cases infected (PCI) and proportion of the cases death (PCD) per 100,000 populations) with other parameters were calculated using bivariate correlation analyses. Statistical significance of mean differences in COVID-19 variables among developed and developing countries (HDI $\geq 0.788$ as 'developed' and any score lower than that as 'developing') [18] was determined using T-student test. Geographical distribution of COVID-19 and other diseases were drawn and processed using ArcGIS 10.3. Statistical analyses were performed in SPSS (IBM, SPSS version 16) and GraphPad Prism (version 6), and $p$-values $<0.05$ were considered significant. 
A

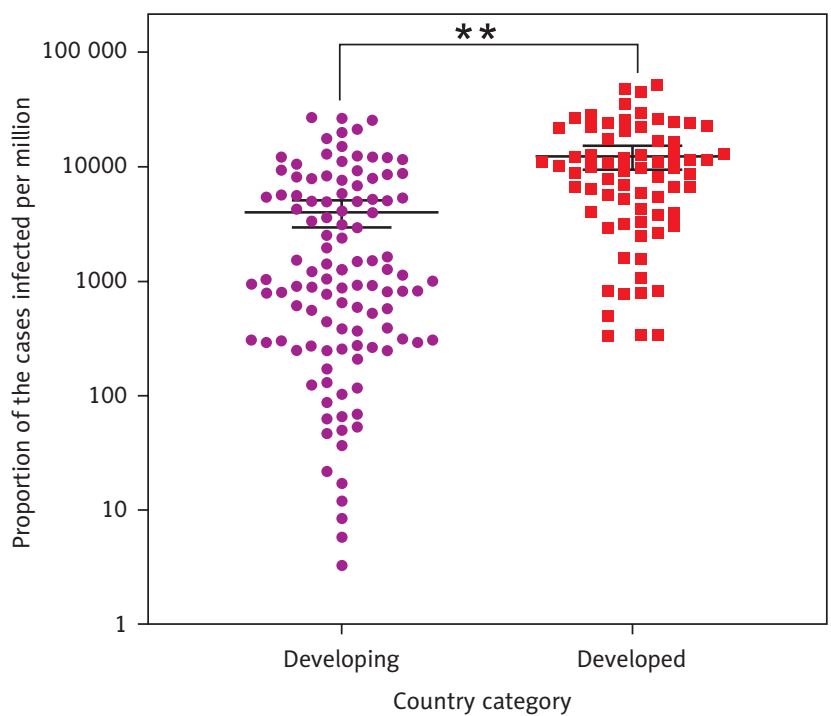

B

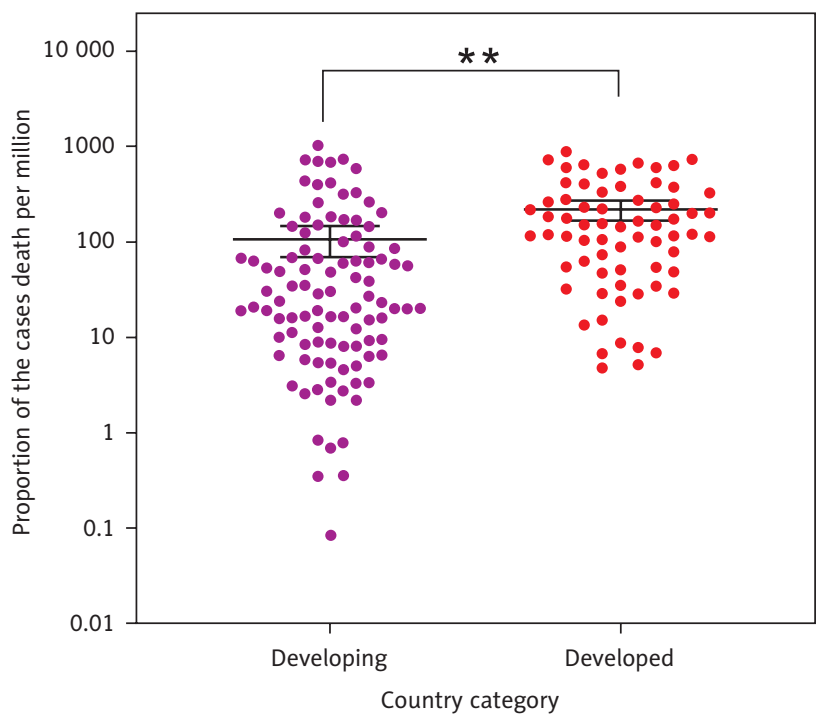

Figure 2. Differences of COVID-19 variables in developed and developing countries, ${ }^{* *} p<0.001$

Table 1. The correlation ( $r$ ) between COVID-19 variables and prevalence of HIV/AIDS and sexually transmitted infections, neoplasms (age-standardized and both sexes), and socio-economic demographic factors

\begin{tabular}{|c|c|c|c|c|c|c|c|c|c|c|c|c|}
\hline Variables & 1 & 2 & 3 & 4 & 5 & 6 & 7 & 8 & 9 & 10 & 11 & 12 \\
\hline 1. $\mathrm{PCl}$ & 1.00 & & & & & & & & & & & \\
\hline 2. PCD & $0.90^{* *}$ & 1.00 & & & & & & & & & & \\
\hline 3. Median age & $0.51^{\star *}$ & $0.47^{\star *}$ & 1.00 & & & & & & & & & \\
\hline 4. Aged > 65 & $0.43^{* *}$ & $0.47^{\star *}$ & $0.90^{* *}$ & 1.00 & & & & & & & & \\
\hline 5. Aged > 70 & $0.43^{\star *}$ & $0.47^{\star *}$ & $0.90^{\star *}$ & $0.99^{\star *}$ & 1.00 & & & & & & & \\
\hline 6. GDP & $0.58^{\star *}$ & $0.50^{\star *}$ & $0.84^{\star *}$ & $0.68^{\star *}$ & $0.68^{\star *}$ & 1.00 & & & & & & \\
\hline 7. LE & $0.56^{* *}$ & $0.50^{* *}$ & $0.87^{* *}$ & $0.78^{\star *}$ & $0.79^{* *}$ & $0.85^{* *}$ & 1.00 & & & & & \\
\hline 8. HIV and SD & $-0.43^{\star \star}$ & $-0.37^{\star \star}$ & $-0.70^{\star \star}$ & $-0.61^{\star \star}$ & $-0.60^{\star *}$ & $-0.66^{\star *}$ & $-0.76^{* *}$ & 1.00 & & & & \\
\hline 9. HIV and SI & $-0.38^{\star \star}$ & $-0.36^{\star *}$ & $-0.69^{\star \star}$ & $-0.59^{\star \star}$ & $-0.58^{\star *}$ & $-0.63^{* *}$ & $-0.70^{\star *}$ & $0.86^{* *}$ & 1.00 & & & \\
\hline 10. HIV and SP & $-0.40^{\star *}$ & $-0.38^{\star *}$ & $-0.61^{* *}$ & $-0.55^{\star *}$ & $-0.54^{\star *}$ & $-0.62^{\star *}$ & $-0.67^{\star *}$ & $0.75^{\star *}$ & $0.89^{* *}$ & 1.00 & & \\
\hline 11. HIVD & $-0.40^{\star *}$ & $-0.34^{\star *}$ & $-0.64^{\star *}$ & $-0.54^{\star \star}$ & $-0.54^{\star *}$ & $-0.60^{\star *}$ & $-0.70^{\star *}$ & $0.98^{* *}$ & $0.83^{* *}$ & $0.72^{\star *}$ & 1.00 & \\
\hline 12. HIVI & $-0.30^{\star *}$ & $-0.26^{\star *}$ & $-0.47^{\star *}$ & $-0.34^{\star *}$ & $-0.33^{\star *}$ & $-0.43^{* *}$ & $-0.55^{\star *}$ & $0.89^{\star *}$ & $0.75^{\star *}$ & $0.61^{\star *}$ & $0.92^{\star *}$ & 1.00 \\
\hline 13. HIVP & $-0.32^{\star *}$ & $-0.30^{\star *}$ & $-0.50^{* *}$ & $-0.36^{\star \star}$ & $-0.36^{\star \star}$ & $-0.45^{\star \star}$ & $-0.57^{\star *}$ & $0.88^{* *}$ & $0.75^{* *}$ & $0.59^{\star *}$ & $0.92^{* *}$ & $0.96^{* *}$ \\
\hline
\end{tabular}

${ }^{* *} p<0.01,{ }^{*} p<0.05, b$ - prevalence value of disease per 100,000 persons, SDI-socio-demographic index, HIV and SD - deaths of HIVIAIDS and sexually transmitted infections, HIV and SP - prevalence of HIVIAIDS and sexually transmitted infections, HIV and SI - incidence of HIVIAIDS and sexually transmitted infections, HIVD - HIV death rate, HIVI - HIV incidence rate, HIVP - HIV prevalence ratio, HIVIAIDS and sexually transmitted infections

\section{Results}

There were 43,341,451 confirmed cases and 1,157,509 deaths of COVID-19 in all countries and territories around the world, up to October 25, 2020. The highest number of deaths was reported to be in European (21\%) and American (54\%) countries (Figure 1).

The analysis of groups illustrated that PCI and PCD variables significantly differed between developed and developing countries $(p>0.05)$ (Figure 2). Correlation coefficients demonstrated that PCI and PCD had significantly negative correlation with prevalence, incidence, and deaths from HIV/AIDS, and sexually transmitted infections $(p<0.001)$ (Table 1). Figures 3 and 4 indicate the distribution of the variables of HIV/AIDS and sexually transmitted infections (prevalence, incidence, and death).

\section{Discussion}

This ecological study presented a report on correlation between the distribution of COVID-19 and the prevalence, 
A

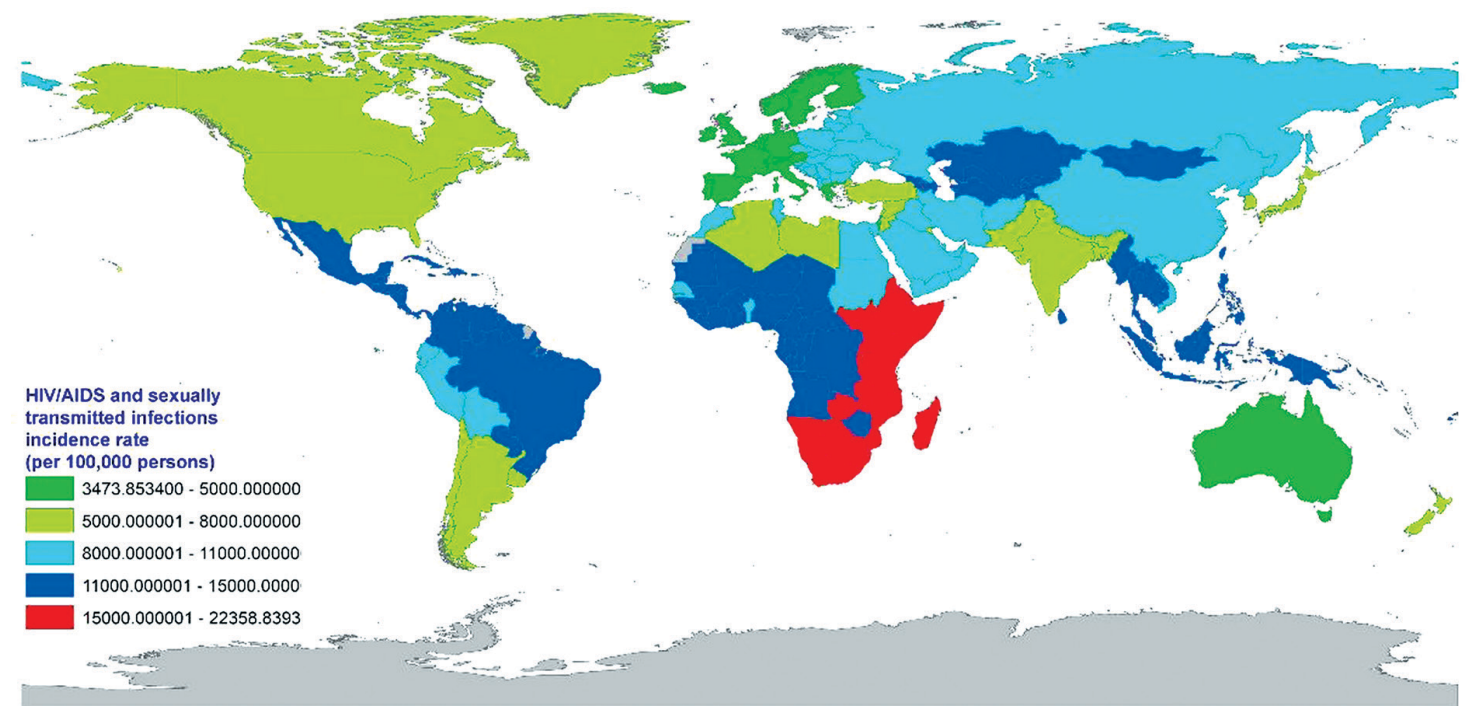

B

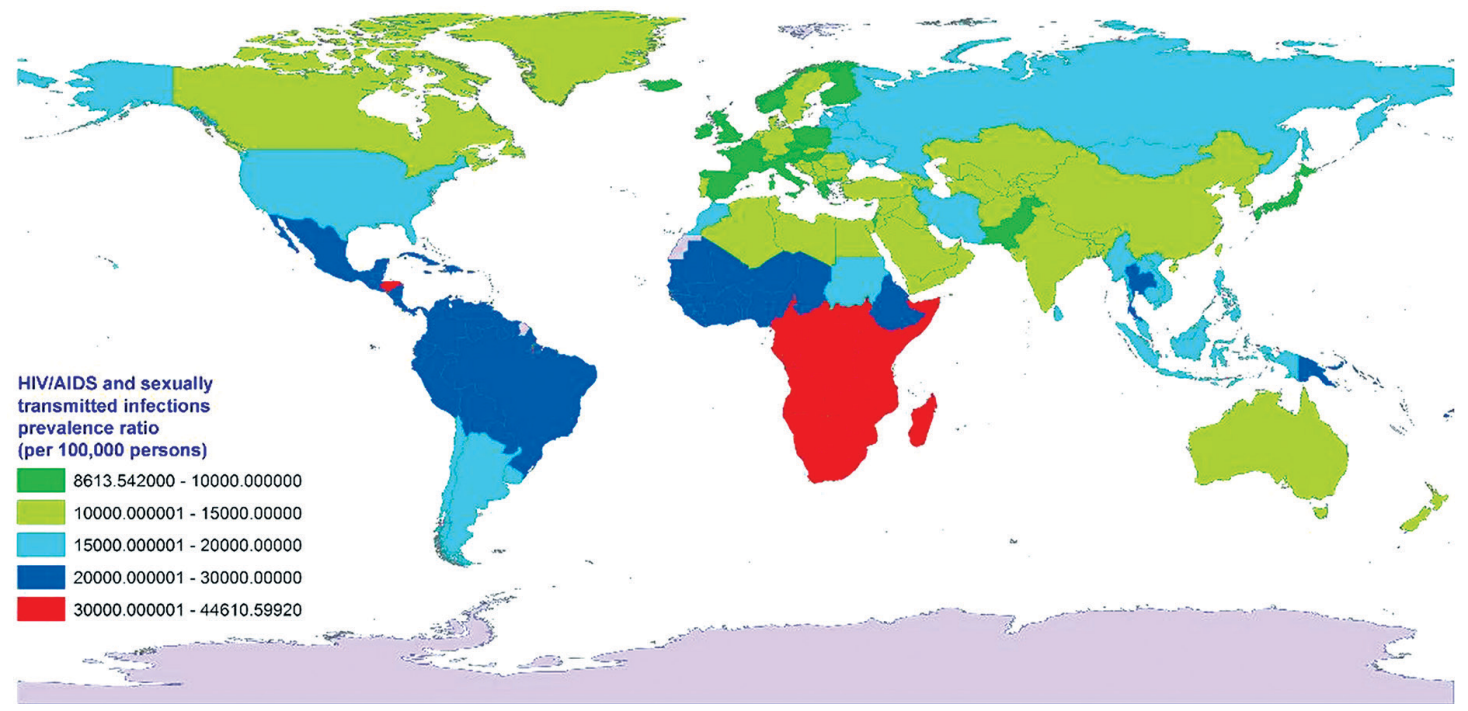

C

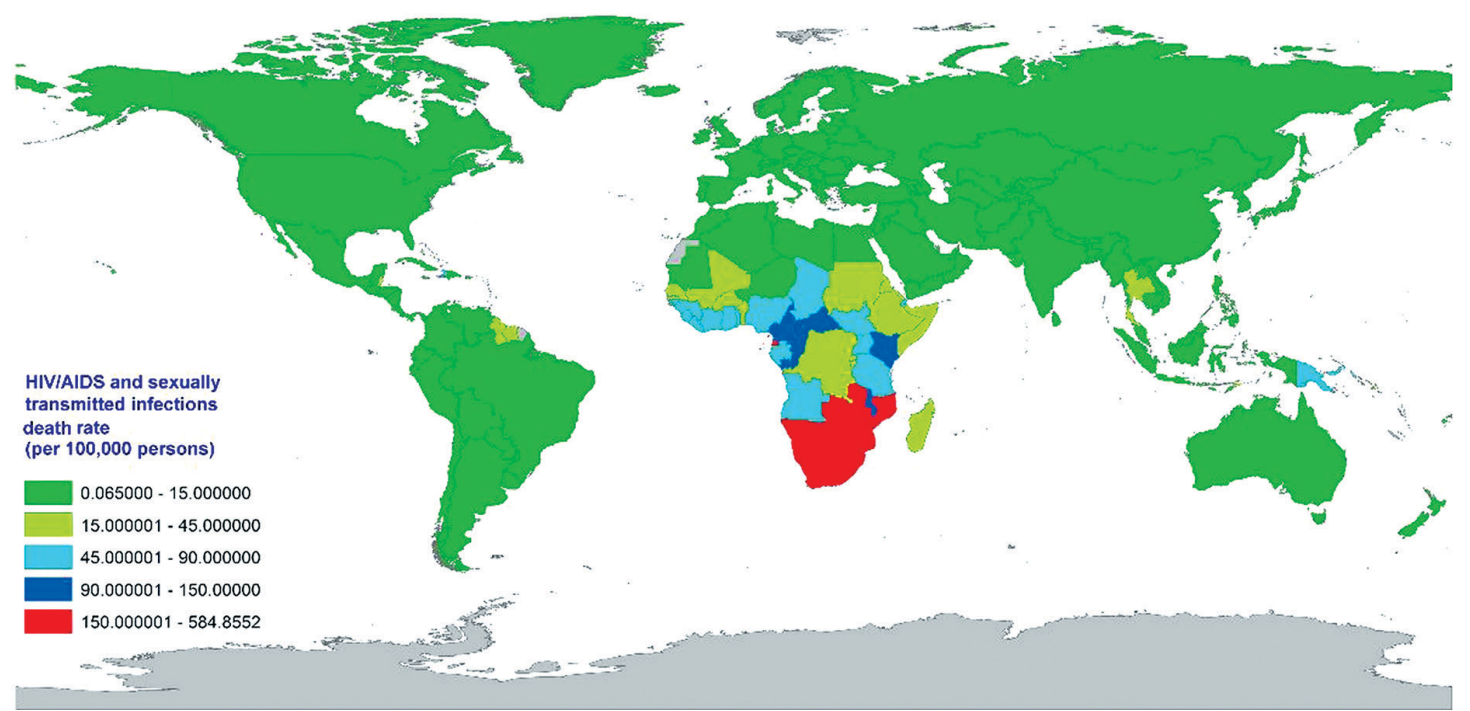

Figure 3. Incidence, prevalence, and mortality of HIV/AIDS and sexually transmitted infections around the world in 2019 based on GBD data 
A

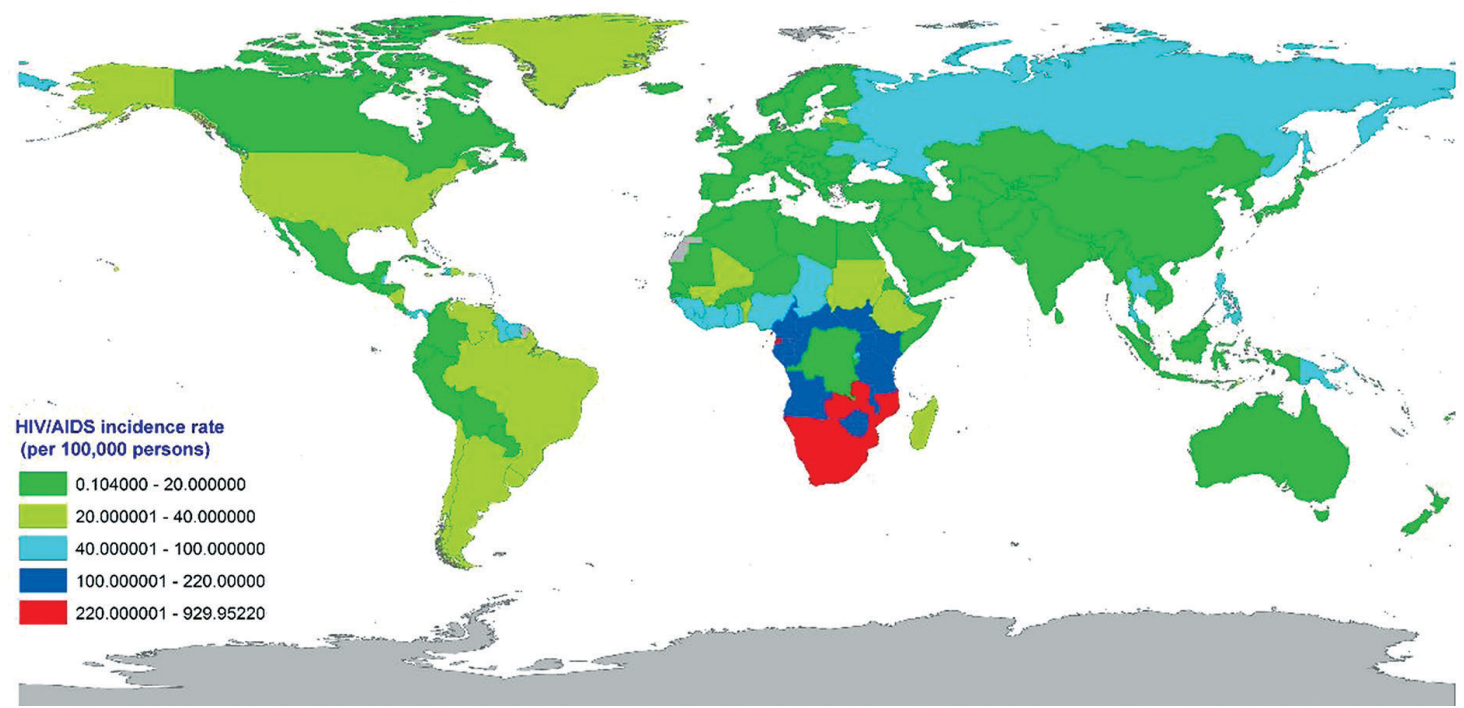

B

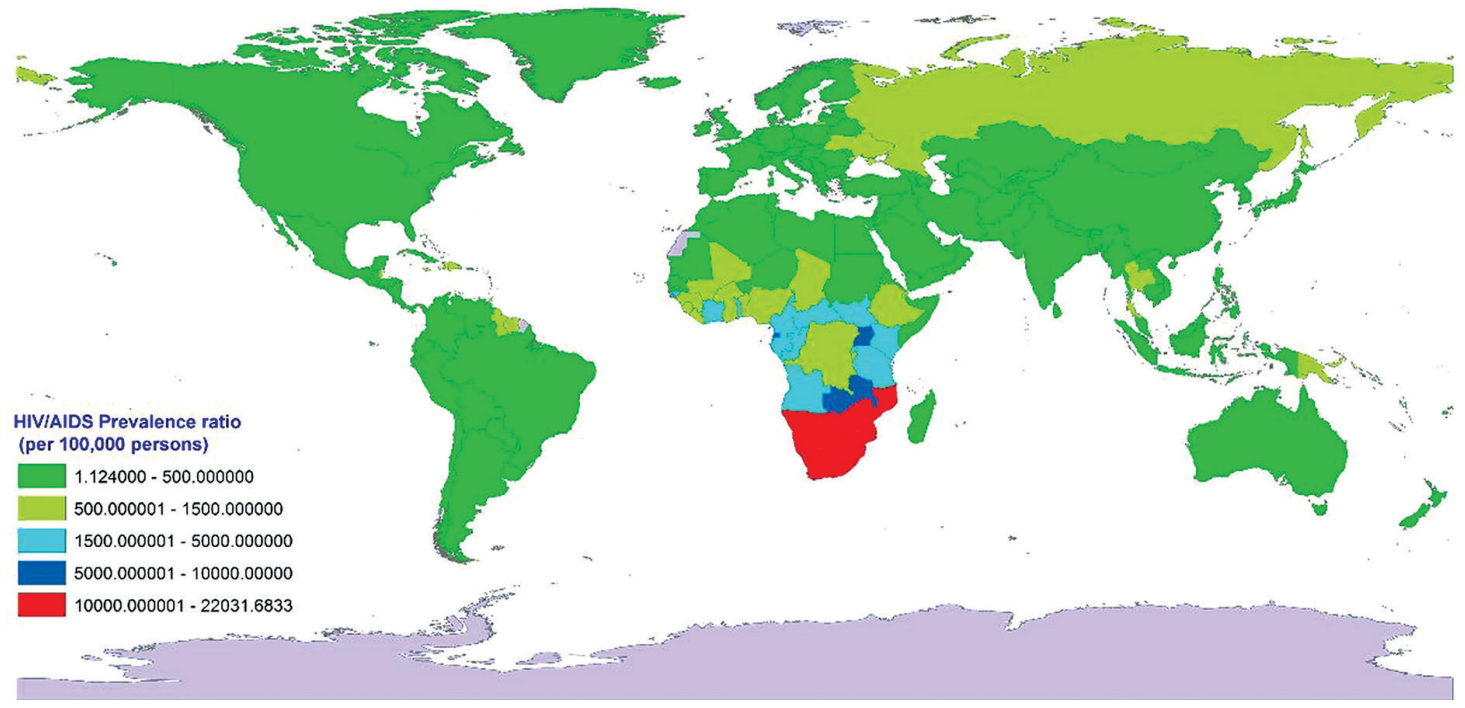

C

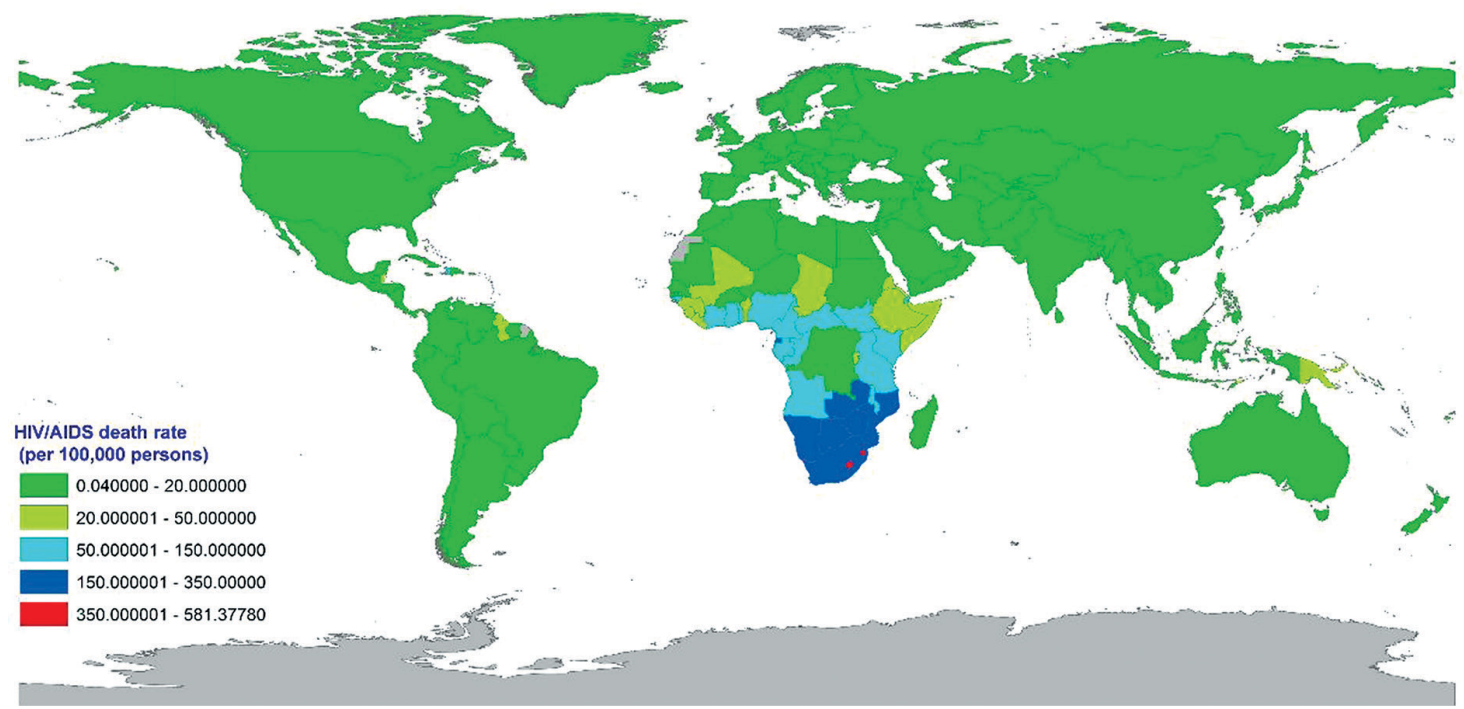

Figure 4. Incidence, prevalence, and mortality of HIV/ AIDS around the world in 2019 based on GBD data 
incidence, and deaths from HIV/AIDS among countries. Many factors effectively increase coronavirus's incidence and death ratio, but more comprehensive and practical analysis is needed to discover the factors that increase COVID-19 incidence and death [19]. It is important to note, that COVID-19 distribution can also differ between urban and rural areas [20,21]. These prior published studies mention that the differences reported are more possible due to country-specific resources and healthcare systems.

The main results of the current study showed that the distribution of the COVID-19 disease was significantly lower in countries with higher rates of HIV/ AIDS (Table 1). This can have several reasons. Most people living with HIV/AIDS are residing in sub-Saharan Africa [22], and these patients do not have access to healthcare during the COVID-19 pandemic. Hence, it seems that the number of COVID-19 patients in such countries is high due to non-compliance with health guidelines $[23,24]$. However, these countries do not have access to COVID-19 test tools due to low-income economy and poverty [25]. But, more importantly, people with HIV benefit from ART, which is currently a potential treatment for a SARS-COV-2 infection [14, 26-28]. This factor may contribute to the low number of COVID-19 cases and deaths in these countries. Karmen-Tuohy et al. reported that HIV status did not considerably impact clinical outcomes in COVID-19 patients [12]. Also, Del Amo et al. founded that HIV patients receiving tenofovir disoproxil fumarate (TDF)/emtricitabine (FTC) had a lower risk for COVID-19 than those receiving other therapies [27]. However, more detailed studies, including cohort and clinical trials, are needed to investigate this hypothesis.

Other results demonstrate a significantly positive association between the incidence and death of COVID-19 and median age (also age up to 65 and 70). Old age is one of the main risk factors for COVID-19 complications in countries with older population [29]. Since the beginning of the pandemic, the elderly have had the highest mortality rate. Recent reports have indicated that countries with older people and a greater number of individuals living in nursing homes are vulnerable to coronavirus [30, 31].

This study had several limitations, including the fastchanging pattern of the pandemic and deficiencies related to the data. In addition, there are many factors that may affect COVID-19 incidence and mortality, including population density as well as climate and air pollution factors. On the other hand, local and national interactions, such as isolation and quarantine programs, social distancing, and travel restrictions could be widely beneficial to dealing with COVID-19 in different regions. We should also address inherent limitations and misconception of ecological research to some extent. The authors believe that the current work can provide researchers with a more realistic understanding of the distribution pattern of the COVID-19 incidence and death ratio and the associated contributing factors.

In conclusion, the present findings show that in countries with high prevalence of HIV/AIDS, the COVID-19 cas- es and death ratio were low. Therefore, it seems that factors, such as drug using, ART, economic, social and cultural status, and type of health services play a role in the COVID-19 distribution. For this reason, more extensive studies on COVID-19 in HIV-positive patients are required in low and lower-middle income countries.

\section{Acknowledgements}

The authors would like to thank Torbat Heydariyeh of University of Medical Sciences for financial support (IR.THUMS.REC.1399.003).

\section{Funding}

This study was supported by Torbat Heydariyeh University of Medical Sciences (grant number: 99000007).

\section{Conflict of interest}

The authors have no conflict of interest.

\section{References}

1. World Health Organization. Coronavirus disease 2019 (COVID-19): situation report, 72. 2020.

2. Taherizadeh M, Tabibzadeh A, Panahi M, et al. An introduction to SARS Coronavirus 2; Comparative analysis with MERS and SARS coronaviruses: a brief review. Iranian J Public Health 2020; 49 (Suppl 1).

3. Worldometer. COVID-19 Coronavirus Pandemic. 2020. Available from: https://www.worldometers.info/coronavirus/?.

4. Sohrabi C, Alsafi Z, O'Neill N, et al. World Health Organization declares global emergency: a review of the 2019 novel coronavirus (COVID-19). Int J Surg 2020; 76: 71-76.

5. Mirzaei H, McFarland W, Karamouzian M, Sharifi H. COVID-19 among people living with HIV: a systematic review. AIDS Behav 2020; doi: 10.1007/s10461-020-02983-2 [Epub ahead of print].

6. Lee LY, Cazier JB, Starkey T, et al. COVID-19 prevalence and mortality in patients with cancer and The effect of primary tumour subtype and patient demographics: a prospective cohort study. Lancet Oncol 2020; 21: 1309-1316.

7. Cooper TJ, Woodward BL, Alom S, Harky A. Coronavirus disease 2019 (COVID-19) outcomes in HIV/AIDS patients: a systematic review. HIV Med 2020; doi: 10.1111/hiv.12911 [Epub ahead of print].

8. Sepandi M, Taghdir M, Alimohamadi Y, Afrashteh S, Hosamirudsari H. Factors associated with mortality in COVID-19 patients: a systematic review and meta-analysis. IranJ Public Health 2020; 49: 1211-1221.

9. Chang CC, Crane M, Zhou J, et al. HIV and co-infections. Immunol Rev 2013; 254: 114-142.

10. Richardson S, Hirsch JS, Narasimhan M, et al. Presenting characteristics, comorbidities, and outcomes among 5700 patients hospitalized with COVID-19 in The New York City area. JAMA 2020; 323: 2052-2059.

11. Borobia AM, Carcas AJ, Arnalich F, et al. A cohort of patients with COVID-19 in a major teaching hospital in Europe. J Clin Med 2020; 9: 1733.

12. Karmen-Tuohy S, Carlucci PM, Zervou FN, et al. Outcomes among HIV-positive patients hospitalized with COVID-19. J Acquir Immune Defic Syndr 2020; 85: 6-10. 
13. Mondi A, Cimini E, Colavita F, et al. COVID-19 in people living with HIV: clinical implications of dynamics of the immune response to SARS-CoV-2. J Med Virol 2021; 93: 1796-1804.

14. Tian C, Tang L, Wu J, et al. An HIV-infected patient with coronavirus disease 2019 has a favourable prognosis: a case report. Ann Palliat Med 2021; 10: 5808-5812.

15. Global Burden of Disease Collaborative Network. Global Burden of Disease Study 2019 (GBD 2019) Results. 2020. Available from: http://ghdx.healthdata.org/gbd-results-tool.

16. World_Bank. World Bank Country and Lending Groups. 2019 Available from: https://datahelpdesk.worldbank.org/knowledgebase/articles/906519-world-bank-country-and-lending-groups.

17. UNDP. Human Development Reports. 2018. Available from: http:// hdr.undp.org/en/composite/HDI

18. Xu Z, Yu D, Yin X, Zheng F, Li H. Socioeconomic status is associated with global diabetes prevalence. Oncotarget 2017; 8: 4443444439.

19. Lakshmi Priyadarsini S, Suresh M. Factors influencing the epidemiological characteristics of pandemic COVID 19: a TISM approach Int J Healthcare Manag 2020; 13: 89-98.

20. Paul R, Arif AA, Adeyemi O, Ghosh S, Han D. Progression of COVID-19 from urban to rural areas in the United States: a spatiotemporal analysis of prevalence rates. J Rural Health 2020; 36: 591-601.

21. Peters DJ. Community susceptibility and resiliency to COVID-19 across the rural-urban continuum in the United States. J Rural Health 2020; 36: 446-456.

22. Mehri A, Alimohamadi Y, Mohammadi M, Sepandi M, Khodamoradi F, Eesmaeilzadeh F. Trend of HIV and tuberculosis coepidemics in different regions of World Health Organization during 2003-2017. HIV AIDS Rev 2020; 19: 167-171.

23. Aristide C, Okello S, Bwana M, Siedner MJ, Peck RN. Learning from people with HIV: their insights are critical to our response to The intersecting COVID-19 and HIV pandemics in Africa. AIDS Behav 2020; doi: 10.1007/s10461-020-02955-6 [Epub ahead of print].

24. Carrico AW, Horvath KJ, Grov C, et al. Double jeopardy: methamphetamine use and HIV as risk factors for COVID-19. AIDS Behav 2020; 24: 3020-3023.

25. Nkengasong J. Let Africa into the market for COVID-19 diagnostics. Nature 2020; 580: 565.

26. Shiau S, Krause KD, Valera P, Swaminathan S, Halkitis PN. The burden of COVID-19 in people living with HIV: a syndemic perspective. AIDS Behav 2020; 24: 2244-2249.

27. Del Amo J, Polo R, Moreno S, et al. Incidence and severity of COVID-19 in HIV-positive persons receiving antiretroviral therapy: a cohort study. Ann Intern Med 2020; 173: 536-541.

28. Blanco JL, Ambrosioni J, Garcia F, et al. COVID-19 in patients with HIV: clinical case series. Lancet HIV 2020; 7: e314-e316.

29. Pence BD. Severe COVID-19 and aging: are monocytes the key? Geroscience 2020; 42: 1051-1061.

30. Lim WS, Liang CK, Assantachai P, et al. COVID-19 and older people in Asia: Asian Working Group for Sarcopenia calls to action. Geriatr Gerontol Int 2020; 20: 547-558.

31. Chen M, An W, Xia F, et al. Clinical characteristics of rehospitalized patients with COVID-19 in China. J Med Virol 2020; 92 2146-2151. 